\title{
Fluid Absorption in Isolated Perfused Colonic Crypts
}

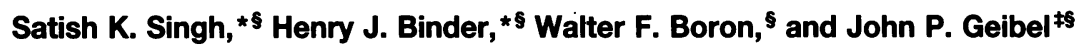 \\ Departments of ${ }^{*}$ Medicine, ${ }^{\ddagger}$ Surgery, and ${ }^{\S}$ Cellular \& Molecular Physiology, Yale University School of Medicine, \\ New Haven, Connecticut 06510
}

\begin{abstract}
A spatial segregation of ion transport processes between crypt and surface epithelial cells is well-accepted and integrated into physiological and pathophysiological paradigms of small and large intestinal function: Absorptive processes are believed to be located in surface (and villous) cells, whereas secretory processes are believed to be present in crypt cells. Validation of this model requires direct determination of fluid movement in intestinal crypts. This study describes the adaptation of techniques from renal tubule microperfusion to hand-dissect and perfuse single, isolated crypts from rat distal colon to measure directly fluid movement. Morphologic analyses of the isolated crypt preparation revealed no extraepithelial cellular elements derived from the lamina propria, including myofibroblasts. In the basal state, crypts exhibited net fluid absorption (mean net fluid movement $=0.34 \pm 0.01 \mathrm{nl} \cdot \mathrm{mm}^{-1} \cdot \min ^{-1}$ ), which was $\mathrm{Na}^{+}$and partially $\mathrm{HCO}_{3}^{-}$dependent. Addition of $1 \mathrm{mM}$ dibutyryl-cyclic AMP, $60 \mathrm{nM}$ vasoactive intestinal peptide, or $0.1 \mathrm{mM}$ acetylcholine to the bath (serosal) solution reversibly induced net fluid secretion (net fluid movement $\left.\approx-0.35 \pm 0.01 \mathrm{nl} \cdot \mathrm{mm}^{-1} \cdot \min ^{-1}\right)$. These observations permit speculation that absorption is a constitutive transport function in crypt cells and that secretion by crypt cells is regulated by one or more neurohumoral agonists that are released in situ from lamina propria cells. The functional, intact polarized crypt described here that both absorbs and secretes will permit future studies that dissect the mechanisms that govern fluid and electrolyte movement in the colonic crypt. (J. Clin. Invest. 1995. 96:2373-2379.) Keywords: fluid secretion • myofibroblasts • cyclic AMP • intestine $\cdot$ crypt
\end{abstract}

\section{Introduction}

Studies of intestinal electrolyte transport performed $>25 \mathrm{yr}$ ago established that net fluid and electrolyte movement in the small and large intestine is determined by both absorptive and secretory processes $(1,2)$. For the past two decades, the accepted paradigm has been that, within a given intestinal seg-

Address reprint requests to John P. Geibel, Departments of Surgery and C\&M Physiology, Yale University School of Medicine, 333 Cedar Street, New Haven, CT 06510. Phone: 203-737-4152; FAX: 203-7374155 .

Received for publication 2 May 1995 and accepted in revised form 25 July 1995.

J. Clin. Invest.

(C) The American Society for Clinical Investigation, Inc 0021-9738/95/11/2373/07 \$2.00

Volume 96, November 1995, 2373-2379 ment, absorptive and secretory processes are spatially segregated along the axis from the superficial colonic surface epithelium (or villous cells in the small intestine) to the gland like crypt: Absorptive processes are present exclusively in the surface epithelial cells in the colon, whereas secretory processes are located exclusively in crypt cells $(3,4)$. However, recent studies in rat colon (5) and jejunum (6) suggest that secretory mechanisms also may be present in surface and villous cells. To date, there has been no direct evidence that absorptive processes are located in crypt epithelium, although it has been suggested, based on theoretical considerations and indirect observations, that crypts absorb fluid $(7,8)$.

Direct functional studies of crypt epithelium have been hindered by the absence of methods to study fluid and electrolyte movement in polarized crypt cells from native intestine. The $\mathrm{T}_{84}$ cell line, derived from a human colonic carcinoma, is wellmaintained as a monolayer and has been used to great advantage as a model of crypt cell function. $T_{84}$ cells in their basal state manifest 0 net $\mathrm{Na}^{+}$and $\mathrm{Cl}^{-}$transport, but several agonists and intracellular messengers induce active $\mathrm{Cl}^{-}$secretion (9). Active $\mathrm{Na}^{+}$absorption has not been demonstrated in $\mathrm{T}_{84}$ cells under any experimental conditions. However, as these cells are derived from a carcinoma, the transport processes present in $T_{84}$ cells may not reflect truly the properties of normal crypt epithelial cells.

A few investigators have used isolated crypts and/or relatively enriched crypt cell preparations to study one or more aspects of crypt cell function, including electrophysiology, cytosolic receptor binding, intracellular $\mathrm{pH}$, cell volume, and ion uptake (10-15). In most of these studies, crypt cell polarity has not been preserved, and in none has fluid and/or ion transport been determined in an intact crypt epithelium. Because epithelial cells are polarized, a thorough understanding of their transport physiology requires that epithelial polarity and intercellular junctions be maintained.

A direct approach to establish whether secretion is indeed an exclusive function of crypt epithelial cells would require study of the rate of fluid movement $\left(J_{v}\right)^{1}$ in intact crypt epithelium independent from surface cells. In the present study, colonic crypts were isolated and perfused simultaneously and independently on their luminal and serosal surfaces. These microperfusion techniques have been used previously in the study of isolated nephron segments (16) and gastric glands (17) and were adapted for the direct determination of $J_{v}$ in isolated colonic crypts. Contrary to the spatial-distribution model, which predicts that crypts only secrete, we found that the isolated colonic crypt absorbs fluid in the basal state. Moreover, addition of agonists that induce active $\mathrm{Cl}^{-}$secretion in native colon and $\mathrm{T}_{84}$ cells, i.e., dibutyryl-cAMP (DBcAMP), vasoactive intesti-

1. Abbreviations used in this paper: ACh, acetylcholine; DBcAMP, dibutyryl cAMP; $J_{v}$, net fluid movement; NHE, Na-H exchange; VIP, vasoactive intestinal peptide. 
nal peptide (VIP), or acetylcholine (ACh), reversibly stimulated fluid secretion in the colonic crypt. Based on these results, the existing model of the spatial distribution of absorptive and secretory processes between colonic surface and crypt cells must be modified; the present work suggests that absorptive processes are constitutively present in crypt cells but that multiple neurohumoral agonists released from one or more lamina propria cells, especially the myofibroblasts, regulate secretion.

\section{Methods}

Luminal perfusion of colonic crypts and determination of $J_{v}$ Nonfasting male Sprague-Dawley rats weighing $100-150 \mathrm{~g}$ were killed; the colons were removed, and single, hand-dissected colonic crypts were perfused using the same approach used in perfusion studies of renal tubules $(16,18)$. The crypts were placed in a temperature-controlled, superfusable $0.25-\mathrm{ml}$ chamber on the stage of an inverted microscope (Carl Zeiss, Thornwood, NY). An assembly of concentric glass micropipettes was used to hold the blind end of the crypt; the perfusion pipette was used to puncture this blind end and introduce the perfusate containing $10 \mu \mathrm{Ci} / \mathrm{ml}$ methoxy- $\left[{ }^{3} \mathrm{H}\right]$ inulin (New England Nuclear, Boston, MA) into the lumen of the crypt. A second set of micropipettes was used to cannulate the open end of the crypt and collect the effluent. Solutions flowed continuously through the lumen with a collection rate of $\sim 4 \mathrm{nl} / \mathrm{min}$. Solutions were delivered near the tip of the perfusion pipette via a fluid exchange pipette system open to atmospheric pressure, as previously described $(19,20)$. Simultaneously, the bath (i.e., serosal or blood-side of the crypt) was superfused continuously in the chamber at a rate of $\sim 3 \mathrm{ml} / \mathrm{min}$. Both lumen and bath solutions were maintained at the same height above the perfusion chamber and were changed without disrupting flow using multiple-inflow single-outflow pressure valves (Minuteman Controls, Wakefield, MA). The order of perturbations was randomized except for the results shown in Fig. 6. Measured aliquots of effluent were sampled with a volume-calibrated pipette. $J_{v}$ was calculated as previously described $(19,20)$ from the rate at which the effluent accumulated in the collection pipette and the concentrations of methoxy- $\left[{ }^{3} \mathrm{H}\right]$ inulin in the perfusate and effluent. [Methoxy ${ }^{3} \mathrm{H}$-inulin] was determined with a liquid scintillation spectrometer (Model 6892; Tracor Analytic, Elk Grove Village, IL) with a counting accuracy of $0.5 \%$. For triplicate samples of the collected fluid, the standard error (SE) of counts ranged from $0.10 \%$ to $0.35 \%$ of mean values. Positive $J_{v}$ values $\left(\mathrm{nl} \cdot \mathrm{mm}^{-1} \cdot \mathrm{min}^{-1}\right)$ indicate net fluid movement from lumen to bath (i.e., absorption); negative values indicate net fluid movement from bath to lumen (i.e., secretion). SE for $J_{v}$ values ranged from 2 to $11 \%$ of the mean value, averaging $\sim 5 \%$.

The bath solution was routinely assayed for methoxy- ${ }^{3} \mathrm{H}$-inulin, and experiments were discarded in which bath [methoxy- ${ }^{3} \mathrm{H}$-inulin] exceeded background. A 15-min interval followed all solution changes, after which timed collections of luminal effluent were initiated. Each data point in the figures represents the average of three $\sim 10$-min collections of effluent. At the end of each experiment, the viability of the crypt was assessed with trypan blue, and experiments in which cells failed to exclude dye were disregarded $(<15 \%$ of experiments $)$. The $\mathrm{HCO}_{3}$-Ringer solution contained (in millimolar): $125 \mathrm{NaCl} ; 5 \mathrm{KCl} ; 1.2$ $\mathrm{CaCl}_{2} ; 1.2 \mathrm{MgSO}_{4} ; 2 \mathrm{NaH}_{2} \mathrm{PO}_{4} ; 10.2$ glucose; and $22 \mathrm{NaHCO}_{3}$. The solution was equilibrated with $5 \% \mathrm{CO}_{2}$ and adjusted to an osmolality of $300-310 \mathrm{mOsm} / \mathrm{kg}$. pH of all solutions was 7.40 at $37^{\circ} \mathrm{C}$. In the $\mathrm{Na}^{+}$-free solution, $\mathrm{NaCl}$ and $\mathrm{NaHCO}_{3}$ were replaced with equivalent amounts of choline- $\mathrm{Cl}$ and choline- $\mathrm{HCO}_{3}$, respectively, and $\mathrm{NaH}_{2} \mathrm{PO}_{4}$ was replaced by $2 \mathrm{mM} \mathrm{H}_{3} \mathrm{PO}_{4}$. In the nominally $\mathrm{CO}_{2} / \mathrm{HCO}_{3}^{-}$free solutions, $32 \mathrm{mM}$ Hepes replaced $22 \mathrm{mM} \mathrm{NaHCO}$ and the solution was air equilibrated. The one-tailed Student's $t$ test was used to determine statistical significance.

\section{Morphology}

Scanning electron microscopy. Hand-dissected crypts were fixed in Ringer's containing $1 \%$ glutaraldehyde at $4^{\circ} \mathrm{C}$ for $1 \mathrm{~h}$. After being washed three times in PBS the crypts were postfixed for $1 \mathrm{~h}$ in $1 \%$ $\mathrm{OsO}_{4}$ in $0.1 \mathrm{M}$ sodium cacodylate buffer, then washed. The crypts were then dehydrated in graded ethanol and critical-point-dried using liquid $\mathrm{CO}_{2}$ as the transitional fluid. Individual crypts were then mounted on suitable stubs and sputter-coated with gold. Scanning electron micrography was performed on an electron microscope (ISI $=\mathrm{SS}=40$; Topcon Instruments, Paramus, $\mathrm{NJ}$ ) operating at $10 \mathrm{kV}$.

\section{Immunohistochemistry}

Labeling with PR 2D3, an mAb that reacts with myofibroblasts in the pericryptal sheath (21), was performed as described previously (22). Pieces of paraformaldehyde-fixed, full-thickness tissue were rapidly thawed in PBS containing 10\% DMSO and mounted in Optimal Cutting Temperature Compound ${ }^{\circledR}$ (Miles Laboratories Inc., Elkhart, IN). Cryo sections were cut at 6- $\mu \mathrm{m}$ thickness. The tissue was blocked for nonspecific fluorescent staining in PBS $1 \%$ BSA, and $1 \%$ normal goat serum for $1 \mathrm{~h}$ at $25^{\circ} \mathrm{C}$. The primary antibody, PR 2D3, was provided as a tissue-culture supernatant and was applied undiluted to the tissue for 1 $\mathrm{h}$ at $25^{\circ} \mathrm{C}$ then washed with PBS containing $1 \%$ BSA. Secondary antibody, a goat anti-mouse Fab fragment conjugated to rhodamine (Organon-Teknika Inc., Rockville, MD) was then applied at a dilution of 1:200 for $1 \mathrm{~h}$ and then washed with PBS containing 1\% BSA. Slides were then cover-slipped and edge-sealed.

Single, $1 \%$ glutaraldehyde-fixed hand-dissected crypts in suspension were blocked and labeled identically to the intact tissue sections. Crypts were then transferred to a glass slide, cover-slipped, and edge-sealed as above. Immunofluorescence was examined by confocal microscopy (Bio-Rad Laboratories Instruments, Hercules, CA) with a rhodamine filter set. The intensity of fluorescence emission from labeled tissue was remarkably high, with virtually undetectable nonspecific background staining. No image analysis or intensification was used.

\section{Results}

Morphology and integrity of colonic crypts. Fig. 1 is a scanning electron micrograph of the basolateral surface of a hand-dissected crypt. The crypt appears to be an intact structure lacking extraepithelial cellular elements. Additionally, light and transmission electron microscopy revealed that the hand-dissected crypt was an intact epithelium composed primarily of two cell types, the mucus-containing goblet cells and microvacuolated cells (micrographs not shown). At no time were any lamina propria cellular elements identified.

To confirm further that hand-dissected crypts were an isolated epithelium devoid of its myofibroblast-containing pericryptal sheath, immunohistochemical studies were performed with the mAb (PR 2D3). This IgG-class antibody reacts with cells in the pericryptal sheath identified as myofibroblasts (21). Immunofluorescent activity was readily identified in the lamina propria of intact rat colon (Fig. $2 A$ ). In contrast, PR 2D3 did not react with any cellular elements in the hand-dissected crypts (Fig. $2 C$ ). These immunohistochemical experiments, together with the transmission and scanning electron microscopic studies, confirm that the isolated crypt preparation is devoid of subepithelial myofibroblasts.

Basal fluid movement and effect of $\mathrm{Na}^{+}$removal. In the first series of experiments, the direction and rate of fluid movement in colonic crypts in the basal state was determined during perfusion of lumen and bath with identical $\mathrm{HCO}_{3}^{-}$-containing Ringerlike solutions. Fig. 3 presents the results of six separate experiments. In each case, constant rates of fluid absorption were present over three successive 10-min samples. As shown in Fig. 3 , bar $a$, the mean basal $J_{v}$ was $0.27 \pm 0.03 \mathrm{nl} \cdot \mathrm{mm}^{-1} \cdot \mathrm{min}^{-1}$. These experiments demonstrate that, in the basal state, isolated 


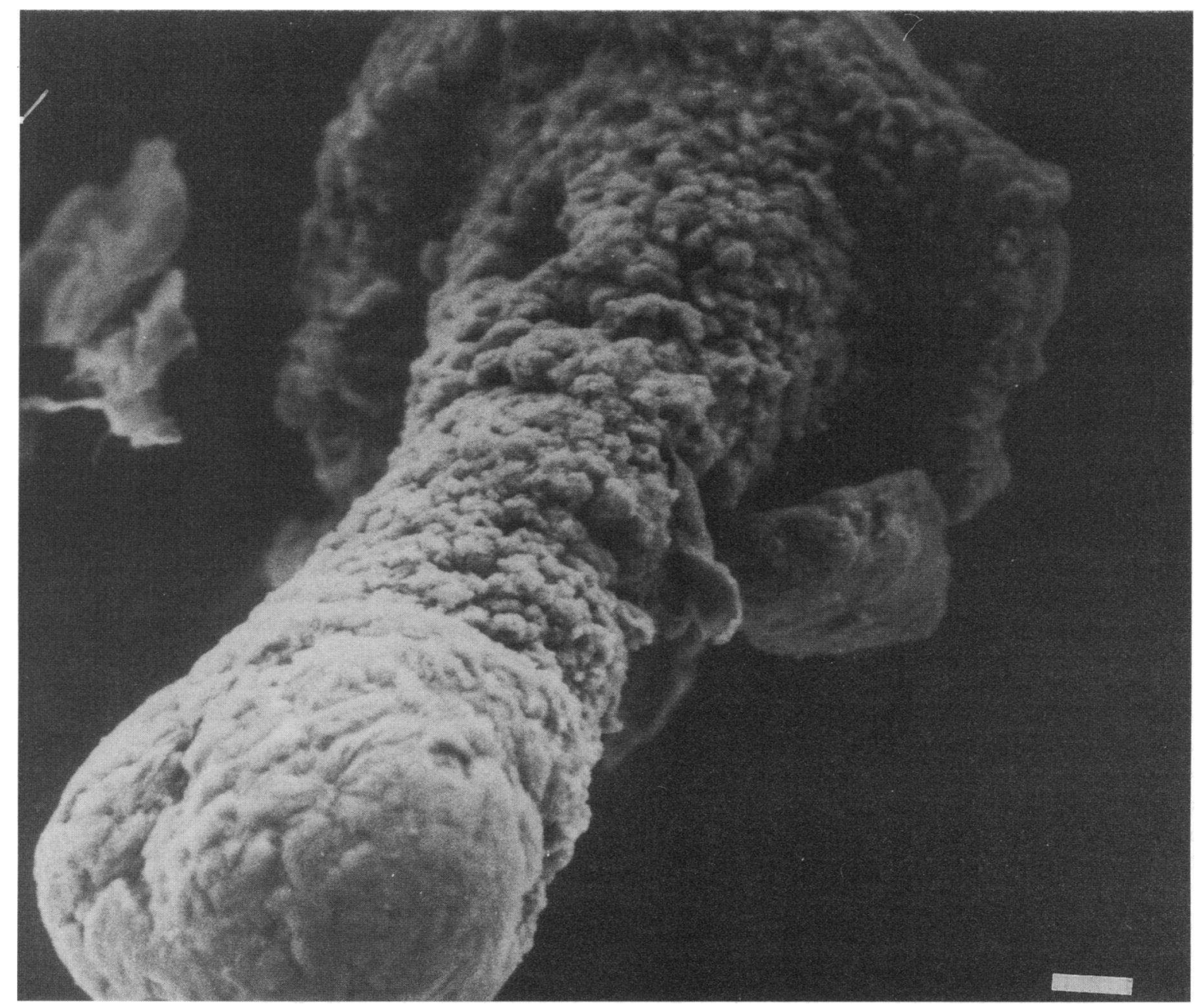

Figure 1. Scanning electron micrograph of an isolated crypt. Crypt length is typically $400 \mu \mathrm{m}$. The isolated, hand-dissected crypt is an intact epithelial unit without associated cellular elements. The white scale marker represents $10 \mu \mathrm{m}$.

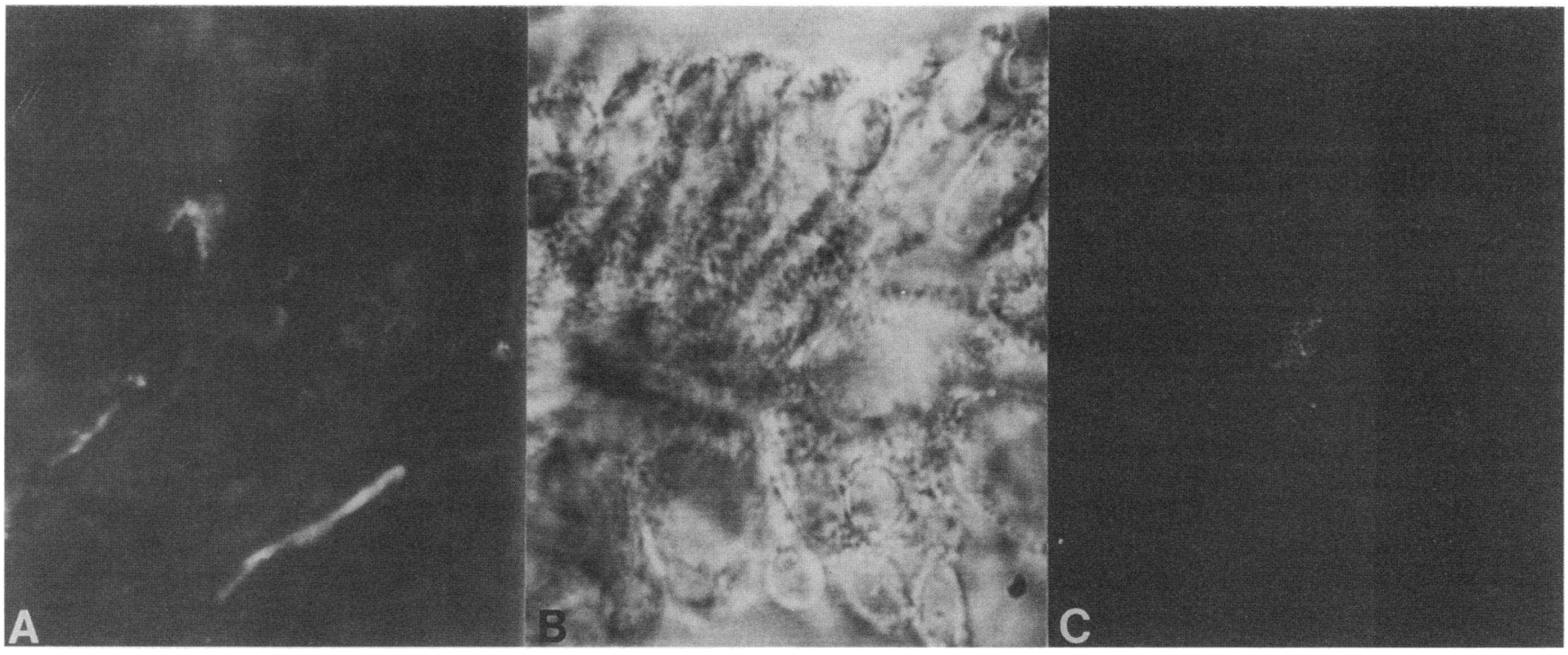

Figure 2. Immunohistochemistry for localization of myofibroblasts using mAb PR 2D3. (A) Mucosal section through colonic tissue from which crypts have not been dissected. Staining is positive in a rimlike distribution adjacent to the basolateral surfaces of both crypt and surface epithelium. There was no detectable nonspecific staining. $(B)$ Transmitted image of the hand-dissected crypt shown in $C$ fixed in paraformaldehyde. $(C)$ Rhodamine fluorescence image of $B$, stained for pericryptal myofibroblasts. No fluorescence was detectable. 


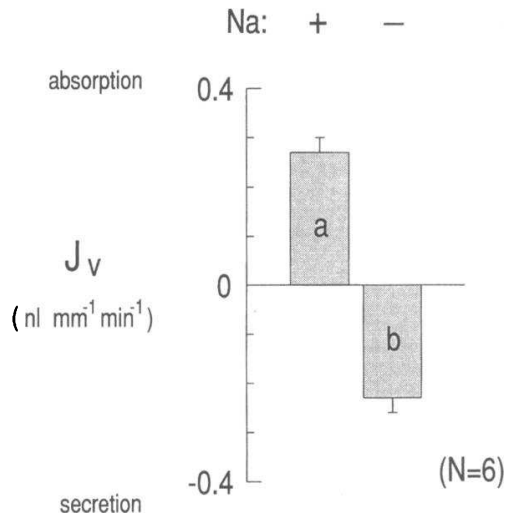

value indicates secretion. The vertical hash marks indicate SEM; the number of paired observations is in parentheses.

perfused crypts of rat distal colon absorb fluid. This observation conflicts with the established model that fluid secretion is the exclusive function of crypt cells.

The role of $\mathrm{Na}^{+}$in crypt fluid absorption was examined next. In both in vivo and in vitro studies of rat distal colon, water absorption has been found to be $\mathrm{Na}^{+}$dependent $(2,23$, 24). In the present studies, choline was substituted for $\mathrm{Na}^{+}$in both the lumen and bath. In the absence of $\mathrm{Na}^{+}$, mean $J_{v}$ was $-0.23 \pm 0.03 \mathrm{nl} \cdot \mathrm{mm}^{-1} \cdot \mathrm{min}^{-1}$, indicating that fluid absorption in the crypt was $\mathrm{Na}^{+}$dependent (Fig. 3, bar $b$ ).

Reversible induction of a secretory state by dibutyryl$c A M P$. Given that fluid absorption (not fluid secretion) was observed in the basal state, experiments were performed to establish whether isolated colonic crypts are capable of secretion. Thus, the effect on $J_{v}$ of DBcAMP, a permeant cAMP analogue that induces colonic $\mathrm{Cl}^{-}$secretion both in native rat colon (25) and in $\mathrm{T}_{84}$ cells (26), was determined. Fig. 4 presents the results of six experiments performed in $\mathrm{HCO}_{3}^{-}$-containing solutions in which $J_{v}$ was determined under control conditions, in the presence of $1 \mathrm{mM}$ basolateral DBcAMP, and finally after washout

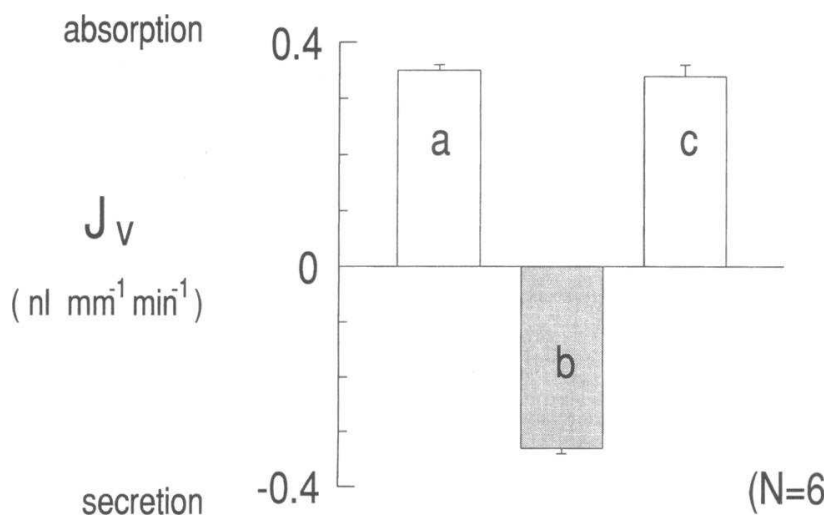

Figure 4. Effect of dibutyryl-cAMP on $J_{v} . J_{v}$ was measured in paired experiments on isolated perfused colonic crypts in the resting state (bar $a$ ), in the presence of $1 \mathrm{mM}$ DBcAMP added to the bath solution (bar $b$ ), and after washout of the drug ( $\operatorname{bar} c$ ). Both bath and lumen were perfused with a $\mathrm{CO}_{2} / \mathrm{HCO}_{3}^{-}$Ringer. Collections of luminal effluent were begun after $15 \mathrm{~min}$ of exposure to each solution. A positive value for $J_{v}$ indicates net absorption, a negative value indicates net secretion. The vertical hash marks indicate SEM; the number of paired observations is in parentheses.

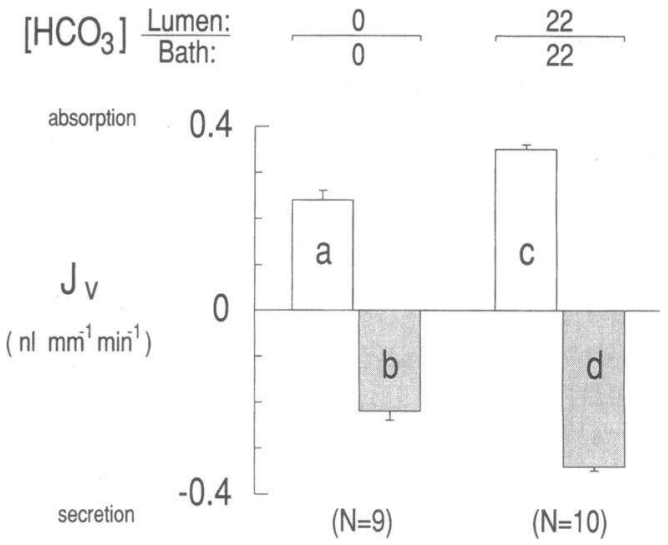

Figure 5. Effect of $\mathrm{CO}_{2} / \mathrm{HCO}_{3}^{-}$on the response of $J_{v}$ to DBcAMP. Bars $a$ and $c$ show $J_{v}$ at rest, whereas bars $b$ and $d$ show $J_{v}$ after the addition of $1 \mathrm{mM}$ DBcAMP to the bath solution. The experiments conducted in the absence of $\mathrm{CO}_{2} / \mathrm{HCO}_{3}^{-}$(bars $a$ and $b$ ) and in the presence of $\mathrm{CO}_{2} / \mathrm{HCO}_{3}^{-}$(bars $c$ and $d$ ) were paired. A positive value for $J_{v}$ indicates net absorption, a negative value indicates net secretion. The vertical hash marks indicate SEM; numbers of paired observations are in parentheses.

of the DBcAMP. In the absence of DBcAMP, the mean $J_{v}$ was $+0.35 \pm 0.03 \mathrm{nl} \cdot \mathrm{mm}^{-1} \cdot \mathrm{min}^{-1}$, indicating net fluid absorption (Fig. 4, bar $a$ ). Exposure to DBcAMP induced net fluid secretion; $J_{v}$ averaged $-0.33 \pm 0.03 \mathrm{nl} \cdot \mathrm{mm}^{-1} \cdot \min ^{-1}($ Fig. 4 , bar $b$ ). In paired experiments, the change in $J_{v}$ elicited by DBcAMP $\left(\Delta J_{v}\right.$, condition $b$ vs $a$ ) was $-0.69 \pm 0.02 \mathrm{nl} \cdot \mathrm{mm}^{-1} \cdot \mathrm{min}^{-1}$. After washout of DBcAMP, fluid movement in the crypt returned to a rate of absorption that was indistinguishable from that of the initial control period (Fig. 4, bar $c$ ).

The effects of $\mathrm{CO}_{2} / \mathrm{HCO}_{3}^{-}$and $\mathrm{DBcAMP}$ on $\mathrm{J}_{v}$. Fig. 5 presents the effects of $1 \mathrm{mM}$ DBcAMP on fluid movement both when $\mathrm{CO}_{2} / \mathrm{HCO}_{3}^{-}$was absent and when $\mathrm{CO}_{2} / \mathrm{HCO}_{3}^{-}$was present in the bath and lumen. Regardless of the $\mathrm{CO}_{2} / \mathrm{HCO}_{3}^{-}$status, DBcAMP converted net fluid absorption to net fluid secretion. It is interesting to note that the addition of $\mathrm{CO}_{2} / \mathrm{HCO}_{3}^{-}$to bath and lumen caused a $48 \%$ increase in resting rate of fluid absorption (Fig. 5, $c$ vs $a$ ) and a 50\% increase in the change in net fluid movement induced by DBcAMP (i.e., Fig. 5, conditions $b$ vs $a$ compared with conditions $d$ vs $c$ ). Thus $\Delta J_{v}$ increased from $-0.46 \pm 0.04 \mathrm{nl} \cdot \mathrm{mm}^{-1} \cdot \mathrm{min}^{-1}$ in the absence of $\mathrm{CO}_{2} /$ $\mathrm{HCO}_{3}^{-}$to $-0.69 \pm 0.02 \mathrm{nl} \cdot \mathrm{mm}^{-1} \cdot \mathrm{min}^{-1}$ in the presence of $\mathrm{CO}_{2} /$ $\mathrm{HCO}_{3}^{-}(P<0.001)$. It is possible that $\mathrm{CO}_{2} / \mathrm{HCO}_{3}^{-}$stimulates absorption and secretion either directly, by promoting $\mathrm{HCO}_{3}^{-}$ transport, or indirectly, by stimulating other transport systems (27).

Effects of other agonists on $J_{v}$. Since DBcAMP is an intracellular second messenger, experiments were also performed with VIP and ACh, both of which stimulate active $\mathrm{Cl}^{-}$secretion in isolated colonic epithelia $(25,28)$. Fig. 6 presents the results of the effect of VIP and ACh on $J_{v}$, and for comparison includes all of the control (Fig. 6, bar $a$ ) and DBcAMP (Fig. 6, bar $b$ ) data obtained in the presence $\mathrm{CO}_{2} / \mathrm{HCO}_{3}^{-}$. VIP acts by stimulating adenylyl cyclase via receptors on the basolateral membrane $(25,29)$, while $\mathrm{ACh}$ is a neurotransmitter that stimulates active $\mathrm{Cl}^{-}$secretion in both small and large intestine by increasing intracellular $\left[\mathrm{Ca}^{++}\right]$which activates basolateral $\mathrm{K}^{+}$channels, hyperpolarizing the cell and promoting $\mathrm{Cl}^{-}$efflux across the 


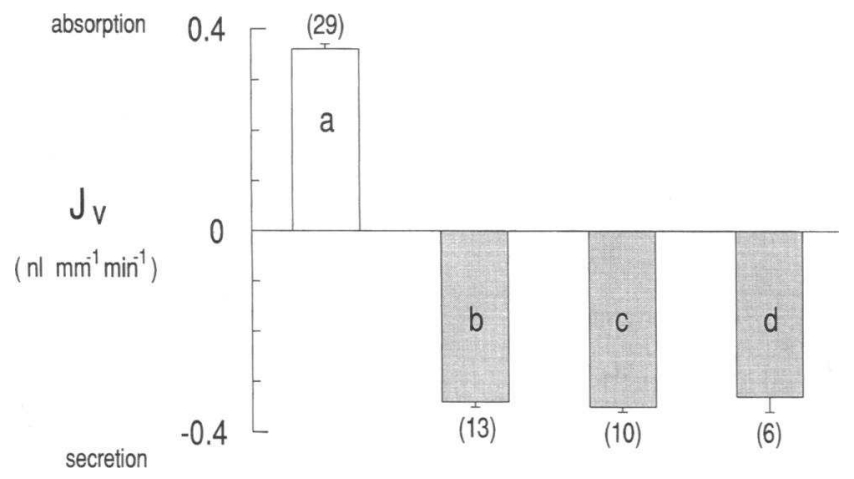

Figure 6. Effect of DBcAMP, VIP, and ACh on $J_{v}$. Results represent unpaired experiments. The standard $\mathrm{CO}_{2} / \mathrm{HCO}_{3}^{-}$-Ringer was used in all studies. Bar $a$ represents the mean resting $J_{v}$ value for all control experiments. $1 \mathrm{mM}$ DBcAMP (bar $b$ ), $60 \mathrm{~nm}$ VIP (bar $c$ ), and $100 \mu \mathrm{M}$ ACh (bar $d$ ) were added to the bath as indicated. A positive value for $J_{v}$ indicates net absorption, a negative value indicates net secretion. The vertical hash marks indicate SEM; numbers of paired observations are in parentheses.

apical membrane $(28,30)$. Adding $60 \mathrm{nM}$ VIP to the bath converted net fluid absorption to net secretion (Fig. 6, bar $c$, mean $\left.J_{v}=-0.35 \pm 0.01 \mathrm{nl} \cdot \mathrm{mm}^{-1} \cdot \mathrm{min}^{-1}\right)$. Similarly, addition of $100 \mu \mathrm{M}$ ACh to the bath in the presence of $\mathrm{CO}_{2} / \mathrm{HCO}_{3}^{-}$also induced net fluid secretion (Fig. 6, bar $d$, mean $J_{v}$ $=-0.33 \pm 0.03 \mathrm{nl} \cdot \mathrm{mm}^{-1} \cdot \mathrm{min}^{-1}$ ) at a rate indistinguishable from that produced by either DBcAMP or VIP.

\section{Discussion}

The spatial-distribution model. The present studies provide evidence that the crypt epithelium of the distal colon has the capacity for both fluid absorption and secretion. Our observations appear to conflict with the established model that secretory processes represent a crypt cell function, whereas absorptive processes are solely a surface epithelial cell function. This established model that has been widely accepted as dogma for $25 \mathrm{yr}$ evolved primarily from circumstantial evidence, without direct measurement of fluid movement in the colonic crypt. The observations that provided the initial basis for this model of specialized function were studies of cholera enterotoxin in the canine and rabbit small intestine $(31,32)$. Cycloheximide, a potent inhibitor of protein synthesis, partially inhibited cholera toxininduced fluid secretion and decreased mitotic figures in crypts, but did not alter glucose-stimulated fluid absorption (31). Because protein synthesis was thought to occur primarily in crypt cells, these studies were interpreted to mean that fluid secretion, but not fluid absorption, occurs in crypt cells, whereas fluid absorption, and presumably not fluid secretion, occurs in villous cells. In contrast, exposure of jejunal mucosa to hyperosmolar solutions resulted in histologic damage in villous cells and reduced glucose $\cdot$ absorption but did not affect either crypt cell morphology or cholera toxin-induced fluid secretion (32).

The spatial-distribution model has been supported by other observations. For example, electrophysiologic studies on the rabbit distal colon (3) found that luminal application of 0.1 $\mathrm{mM}$ amiloride, an inhibitor of apical $\mathrm{Na}^{+}$channels, increased apical membrane resistance of surface epithelial cells but had no effect in crypt cells. In contrast, $\mathrm{PGE}_{2}$ increased apical mem- brane conductance in crypt but not surface epithelial cells. Further, $\mathrm{PGE}_{2}$ elicited formation of microscopic fluid droplets in the areas overlying crypt openings but not in areas between crypt openings (3).

However, more recent studies suggest that the spatial-distribution model may be an oversimplification: Villous epithelial cells in the rabbit jejunum exhibit a $\mathrm{Cl}^{-}$-dependent depolarization of apical membrane potentials when exposed to $\mathrm{PGE}_{2}(5)$, and surface epithelial cells in the rat distal colon exhibit a $\mathrm{Cl}^{-}$ conductance when exposed to DBcAMP (6). Although neither study directly demonstrated $\mathrm{Cl}^{-}$secretion, the work is consistent with the notion that surface/villous cells are capable of secretion. In addition, theoretical considerations led Naftalin et al. to propose that colonic crypt cells absorb a hypertonic fluid $(7,8,33)$. As previous studies have not directly assessed the absorptive function of crypt epithelial cells, a method to perfuse colonic crypts was required. Previous experience with both renal tubular and gastric gland microperfusion $(17,20)$ permitted the development of the present methods for the isolation and microperfusion of hand-dissected colonic crypts. With these methods the resting rate of net fluid movement in isolated crypts could be determined directly.

Synthesis of the present data with the classical model. The present observations are not necessarily inconsistent with the classical spatial-distribution model. Our data on isolated colonic crypts, together with results obtained on the $T_{84}$ cell line, which is considered to represent colonic-crypt epithelial cells, suggest a modification of the classical model. In $\mathrm{T}_{84}$ cells, active $\mathrm{Cl}^{-}$ transport is absent in the basal state, but active $\mathrm{Cl}^{-}$secretion is induced by multiple agonists. Interestingly, active $\mathrm{Cl}^{-}$secretion by $\mathrm{T}_{84}$ cells stimulated with bradykinin or serotonin is significantly enhanced when the $T_{84}$ cells are cocultured with an intestinal fibroblast cell line (34). Bradykinin and serotonin induce the release of eicosanoids from these and other nonintestinal fibroblasts (34). These observations suggest that ion secretion in $T_{84}$ cells is not an intrinsic property of the crypt cell in its basal state but rather is induced by paracrine mediators, such as those released from adjacent myofibroblasts and/or other lamina propria cells. The present observation (Fig. 2) that an $\mathrm{mAb}$ to myofibroblasts reacts with the native rat distal colon, but not with isolated crypts, is consistent with this model.

An extension of this hypothesis is that $\mathrm{Na}^{+}$-dependent fluid absorption is a constitutive property of isolated colonic crypt epithelial cells. The basolateral surfaces of crypt epithelial cells are in close proximity to several lamina propria cells, including myofibroblasts, immune cells, and enteric neurons. Thus, in the absence of these lamina propria cells and their neurohumoral products, net fluid absorption was present. When agonists that induce active $\mathrm{Cl}^{-}$secretion were added to the bath solution, crypts were stimulated to secrete. Thus, when situated in their native milieu, crypts are stimulated by the release of one or more neurohumoral agonists from stimulated myofibroblasts and/or other lamina propria cells resulting in the induction of net fluid secretion (35).

The nature of the resting $\mathrm{Na}^{+}$-dependent absorption in these experiments is unknown. The absence of active $\mathrm{Na}^{+}$absorption in the basal state in $T_{84}$ cells may be, in part, related to their neoplastic origin. Both in vivo perfusion studies and determination of $\mathrm{Na}^{+}$transport across isolated mucosa of the rat distal colon have established that $\mathrm{Na}^{+}$absorption is electroneutral and is consistent with $\mathrm{Na}-\mathrm{H}$ exchange (NHE) (2). Apical membrane vesicles prepared primarily from surface epithelial 
cells of the rat distal colon have confirmed the presence of $\mathrm{Na}$ $\mathrm{H}$ exchange (36-38). However, Rajendran et al. have recently identified a $\mathrm{Na}-\mathrm{H}$ exchange with novel properties in apical membrane vesicles prepared from crypt epithelial cells of rat distal colon (38). In these studies, both $\mathrm{H}^{+}$-gradient stimulation of ${ }^{22} \mathrm{Na}$ uptake in crypt apical membrane vesicles and the recovery of intracellular $\mathrm{pH}$ from an acid load in crypt epithelial cells require the presence of $\mathrm{Cl}^{-}$(38); thus, the $\mathrm{Na}-\mathrm{H}$ exchange in the crypt apical membrane is $\mathrm{Cl}^{-}$dependent, unlike all other $\mathrm{Na}-\mathrm{H}$ exchanges, including that present in surface cell apical membranes. These observations are also consistent with recent in situ hybridization studies that established that the NHE-3 isoform, which has been linked to transepithelial $\mathrm{Na}^{+}$absorption in both rat small and large intestine and rabbit ileum (39, 40 ), is present only in surface epithelial cells, not in crypt epithelial cells of the rat distal colon $(40,41)$. Neither the $\mathrm{Na}-$ $\mathrm{H}$ exchange isoform present in the apical membrane of crypt cells nor the cellular mechanism of $\mathrm{Na}^{+}$absorption in the perfused crypt has been established, but NHE- 2 and NHE-4, which have been identified on Northern blot analyses $(42,43)$, and $\mathrm{Cl}^{-}$-dependent $\mathrm{Na}-\mathrm{H}$ exchange (38) are likely possibilities.

The observation in experiments on unstimulated crypts that the removal of $\mathrm{Na}^{+}$led to net fluid secretion was unexpected (Fig. 3). Because choline was the $\mathrm{Na}^{+}$substitute in these experiments, the observed secretion may have represented the combined effects of both the absence of $\mathrm{Na}^{+}$-dependent absorption and secretion of the organic cation choline $(44,45)$.

In conclusion, this study presents a newly developed method for the study of isolated colonic crypt epithelial cells with an intact polar orientation. Contrary to the existing concept of the spatial distribution of secretory and absorptive processes to crypt and surface cells respectively, net fluid absorption was identified in the crypt under basal conditions. However, agonists (i.e., VIP and $\mathrm{ACh}$ ) and intracellular messengers (i.e., DBcAMP) that are known to induce active $\mathrm{Cl}^{-}$secretion in several epithelia reversibly produced net fluid secretion. These results indicate that absorptive processes are constitutively expressed in crypt epithelial cells while secretory ones are regulated by one or more neurohumoral agonists released from lamina propria cells, including myofibroblasts. This methodology will permit studies that will establish the functional properties of colonic crypt epithelial cells.

\section{Acknowledgments}

We thank Dr. Michael Kashgarian of the Department of Pathology for his morphologic interpretations and for performing immunohistochemical studies. We also thank L. Walmart and T. Ardito for their technical assistance. PR 2D3 was kindly provided by N. Wright, Royal Postgraduate Medical School, London.

This study was supported in part by U. S. Public Health Service (USPHS) research grants DK 14669 (H. J. Binder), DK 30344 (W. F. Boron), and DK 17433 (J. Geibel) from the National Institute of Diabetes, Digestive, and Kidney Diseases, as well as a Connecticut Yankee Ingenuity award (J. Geibel). S. K. Singh was a trainee of USPHS training grant DK 07017 from the National Institute of Diabetes, Digestive, and Kidney Diseases during portions of this study. Dr. Singh is also the recipient of a Glaxo Institute of Digestive Health Basic Research award and has an individual National Research Service Administration award (DK 09001) from the National Institute of Diabetes, Digestive, and Kidney Diseases.

\section{References}

1. Sullivan, S., and M. Field. 1991. Ion transport across mammalian small intestine. In Handbook of Physiology, Section 6: The Gastrointestinal System S. G. Schultz, editor. American Physiological Society, Bethesda, MD. 287-301.

2. Binder, H. J., and G. I. Sandle. 1987. Electrolyte absorption and secretion in the mammalian colon. In Physiology of the Gastrointestinal Tract, 2nd ed L. R. Johnson, editor. Raven Press, Ltd., New York. 1389-1418.

3. Welsh, M. J., P. L. Smith, M. Fromm, and R. A. Frizzell. 1982. Crypts are the site of intestinal fluid and electrolyte secretion. Science (Wash. DC). 218:1219-1221

4. Halm, D. R., and R. A. Frizzell. 1991. Ion transport across the large intestine. In Handbook of Physiology, Section 6: The Gastrointestinal System. S. G. Schultz, editor. American Physiological Society, Bethesda, MD. 257-273.

5. Kockerling, A., and M. Fromm. 1993. Origin of cAMP-dependent $\mathrm{Cl}^{-}$ secretion from both crypts and surface epithelia of rat intestine. Am. J. Physiol. 264:C1294-C1301.

6. Stewart, C. P., and L. A. Turnberg. 1989. A microelectrode study of responses to secretagogues by epithelial cells on villus and crypt of rat small intestine. Am. J. Physiol. 257:G334-G343.

7. Bleakman, D., and R. J. Naftalin. 1990. Hypertonic fluid absorption from rabbit descending colon in vitro. Am. J. Physiol. 258:G377-G390.

8. Pedley, K. C., and R. J. Naftalin. 1993. Evidence from fluorescence microscopy and comparative studies that rat, ovine, and bovine colonic crypts are absorptive. J. Physiol. (Lond.). 460:525-547.

9. Dharmsathaphorn, K., J. A. McRoberts, K. G. Mandel, L. D. Tisdale, and H. Masui. 1984. A human colonic tumor cell line that maintains vectorial electrolyte transport. Am. J. Physiol. 246:G204-G208.

10. Bohme, M., M. Diener, and W. Rummel. 1991. Calcium and cAMPmediated secretory responses in isolated colonic crypts. Pflueg. Arch. Eur. J. Physiol. 419:144-151.

11. Lomax, R. B., C. M. McNicholas, M. Lombes, and G. I. Sandle. 1994. Aldosterone-induced apical $\mathrm{Na}$ and $\mathrm{K}$ conductances are located predominantly in surface cells in rat distal colon. Am. J. Physiol. 266:G71-G82.

12. Teleky, B., G. Hamilton, E. Cosentini, G. Bischof, M. Riegler, T. Koperna, W. Feil, R. Schiessel, and E. Wenzl. 1994. Intracellular pH regulation of human colonic crypt cells. Pflueg. Arch. Eur. J. Physiol. 426:267-275.

13. Sundaram, U., R. G. Knickelbein, and J. W. Dobbins. 1991. Mechanism of intestinal secretion: effect of cyclic AMP on rabbit ileal crypt and villus cells. Proc. Natl. Acad. Sci. USA. 88:6249-6253.

14. Diener, M., C. Helmle-Kolb, H. Murer, and E. Scharrer. 1993. Effect of short-chain fatty acids on cell volume and intracellular $\mathrm{pH}$ in rat distal colon. Pflueg. Arch. Eur. J. Physiol. 424:216-223.

15. Knickelbein, R. G., P. S. Aronson, and J. W. Dobbins. 1988. Membrane distribution of sodium-hydrogen and chloride-bicarbonate exchangers in cryp and villus cell membranes from rabbit ileum. J. Clin. Invest. 82:2158-2163.

16. Burg, M., J. Grantham, M. Abramow, and J. Orloff. 1966. Preparation and study of fragments of single rabbit nephrons. Am. J. Physiol. 210:1293-1298.

17. Waisbren, S. J., J. P. Geibel, I. M. Modlin, and W. F. Boron. 1994 Unusual permeability properties of gastric gland cells. Nature (Lond.). 368:332335.

18. Greger, R., and W. Hampel. 1981. A modified system for in vitro perfusion of isolated renal tubules. Pflueg. Arch. Eur. J. Physiol. 389:175-176.

19. McKinney, T. D., and M. B. Burg. 1977. Bicarbonate and fluid absorption by renal proximal straight tubules. Kidney Int. 12:1-8.

20. Geibel, J. P., G. Giebisch, and W. F. Boron. 1989. Effects of acetate on luminal acidification processes in the $\mathrm{S} 3$ segment of the rabbit proximal tubule. Am. J. Physiol. 257:F586-F594.

21. Richman, P. I., R. Tilly, J. R. Jass, and W. F. Bodmer. 1987. Colonic pericrypt sheath cells: characterisation of cell type with new monoclonal antibody. J. Clin. Pathol. (Lond.). 40:593-600.

22. VanWhy, S. K., F. Hildebrandt, T. Ardito, A. Mann, N. J. Siegel, and M. Kashgarian. 1992. Induction and intracellular localization of HSP-72 after renal ischemia. Am. J. Physiol. 263:F769-F775.

23. Billich, C. O., and R. Levitan. 1969. Effects of sodium concentration and osmolarity on water and electrolyte absorption from the intact human colon. $J$. Clin. Invest. 48:1336-1347.

24. Curran, P. F., and G. F. Schwartz. 1960 . Na, Cl and water transport by rat colon. J. Gen. Physiol. 43:555-571.

25. Racusen, L. C., and H. J. Binder. 1977. Alteration of large intestinal electrolyte transport by vasoactive intestinal peptide in the rat. Gastroenterology. 73:790-796.

26. McCabe, R. D., and K. Dharmsathaphorn. 1988. Mechanism of VIPstimulated chloride secretion by intestinal epithelial cells. Ann. N. Y. Acad. Sci. 527:326-345.

27. Nakhoul, N. L., L. K. Chen, and W. F. Boron. 1993. Effect of basolateral $\mathrm{CO}_{2} / \mathrm{HCO}_{3}^{-}$on intracellular $\mathrm{pH}$ regulation in the rabbit $\mathrm{S} 3$ proximal tubule. $J$. Gen. Physiol. 102:1171-1205.

28. Isaacs, P. E. T., C. L. Corbett, A. K. Riley, P. C. Hawker, and L. A 
Turnberg. 1976. In vitro behavior of human intestinal mucosa. The influence of acetylcholine on ion transport. J. Clin. Invest. 58:535-542.

29. Dharmsathaphorn, K., V. Harms, D. J. Yamashiro, R. J. Hughes, H. J. Binder, and E. M. Wright. 1983. Preferential binding of vasoactive intestinal polypeptide to basolateral membrane of rat and rabbit enterocytes. J. Clin. Invest. 71:27-35.

30. Dharmsathaphorn, K., and S. J. Pandol. 1986. Mechanism of chloride secretion induced by carbachol in a colonic epithelial cell line. J. Clin. Invest. 77:348-354

31. Serebro, H. A., F. L. Iber, J. H. Yardley, and T. R. Hendrix. 1969. Inhibition of cholera toxin action in the rabbit by cycloheximide. Gastroenterology. 56:506-511.

32. McGonagle, T. J., H. A. Serebro, F. L. Iber, T. M. Bayless, and T. R. Hendrix. 1969. Time of onset of action of cholera toxin in dog and rabbit. Gastroenterology 57:5-8.

33. Naftalin, R. J., and K. C. Pedley. 1990. Video enhanced imaging of the fluorescent $\mathrm{Na}^{+}$probe SBFI indicates that colonic crypts absorb fluid by generating a hypertonic interstitial fluid. FEBS Lett. 260:187-194.

34. Berschneider, H. M., and D. W. Powell. 1992. Fibroblasts modulate intestinal secretory responses to inflammatory mediators. J. Clin. Invest. 89:484-489.

35. Sartor, R. B., and D. W. Powell. 1991. Mechanisms of diarrhea in intestinal inflammation and hypersensitivity: immune system modulation of intestinal transport. In Diarrheal Diseases, M. Field, editor. Elsevier Science Publishing Co., Inc., New York. 75-114.

36. Rajendran, V. M., and H. J. Binder. 1990. Characterization of Na-H exchange in apical membrane vesicles of rat colon. J. Biol. Chem. 265:84088414 .
37. Binder, H. J., G. Stange, H. Murer, B. Stieger, and H. P. Hauri. 1986 Sodium-proton exchange in colon brush-border membranes. Am. J. Physiol. 251:G382-G390.

38. Rajendran, V. M., J. P. Geibel, and H. J. Binder. 1995. Chloride dependent $\mathrm{Na}-\mathrm{H}$ exchange: a novel mechanism of $\mathrm{Na}^{+}$transport in colonic crypts. J. Biol. Chem. 270:11051-11054.

39. Tse, C. M., S. R. Brant, M. S. Walker, J. Pouyssegur, and M. Donowitz. 1992. Cloning and sequencing of a rabbit cDNA encoding an intestinal and kidney-specific Na-H exchanger isoform NHE-3. J. Biol. Chem. 267:9340-9346.

40. Bookstein, C., A. M. DePaoli, Y. Xie, P. Niu, M. W. Musch, M. C. Rao and E. B. Chang. 1994. Na/H exchangers, NHE-1 and NHE-3, of rat intestine: expression and localization. J. Clin. Invest. 93:106-113.

41. Cho, J. H., M. W. Musch, A. M. DePaoli, C. M. Bookstein, Y. Xie, C. F. Burant, M. C. Rao, and E. B. Chang. 1994. Glucocorticoids regulate Na-H exchange expression and activity in region- and tissue-specific manner. Am. J. Physiol. 267:C796-C803.

42. Wang, Z., J. Orlowski, and G. E. Shull. 1993. Primary structure and functional expression of a novel gastrointestinal isoform of the rat $\mathrm{Na}-\mathrm{H}$ exchanger. J. Biol. Chem. 268:11925-11928.

43. Orlowski, J., R. A. Kandasamy, and G. E. Shull. 1992. Molecular cloning of putative members of the $\mathrm{Na}-\mathrm{H}$ exchanger gene family. J. Biol. Chem. 267:9331-9339.

44. Dantzler, W. H., and S. K. Bentley. 1978. Fluid absorption with and without sodium in isolated perfused snake proximal tubules. Am. J. Physiol. 234:F68-F79.

45. Rennick, B. R. Renal tubule transport of organic cations. 1981. Am. J. Physiol. 240:F83-F89. 